\title{
XX. An attempt to determine the definite and simple proportions, in which the constituent parts of unorganic substances are united with each other
}

Jacob Berzelius M.R.A.

To cite this article: Jacob Berzelius M.R.A. (1814) XX. An attempt to determine the definite and simple proportions, in which the constituent parts of unorganic substances are united with each other, Philosophical Magazine Series 1, 43:190, 88-101, DOI: 10.1080/14786441408637979

To link to this article: http://dx.doi.org/10.1080/14786441408637979

曲 Published online: 27 Jul 2009.

Submit your article to this journal ๘

ЏII Article views: 3

Q View related articles $\square$ 
les unes aux autres." This is arimirably describing them. Those in the water-lily are round as in fig. 2 . in the Journal just mentioned, and the square sort are found in the vail of the same plant. 'The water-lily is in the present print. (See fig. $5, \mathrm{GG}$.)

To Messrs. Nicholson and Tilloch.

XX. An Attempt to determine the definite and simple Proportions, in which the constituent Parts of unorganic Sulstances are anited with each other. By Jacon Berzelius, Professor of Medicine and Pharmacy, and M.R.A. Stockholm.

[Contisued from p. 51.]

2. Aiamina.

$\mathrm{I}_{\mathrm{N}}$ order to be able to determine the quantity of oxygen contained in alumina, I dissolved some of this earth, which had been precipitated from alum by caustic ammonia, in sulphuric acid; and when the acid would take up no more of it, I filtcred the solution, concentrater it by evaporation, and precipitated the neutral salt from it by the ardition of alcohol. The precipitate was well washed with alcohol, in order to separate any uncombined sulphuric acid which might accidentally be present. The salt thus prepared had completely the taste of alum, but the taste was much stronger. In order to drive off the water, I heated it in a platina crucible over a spirit lamp, and weighed the crucible from time to time; when it lost no more of its weight, I considered the salt as free from water. It melted, swelled up, and exhibited the appearance of alum; at last I was obliged to force it down into the crucible, in order that the heat might be able to penetrate it uniformly. The dry salt appeared not to be soluble in water, and in this respect resembled the dry sulphate of the protoxide of iron, the dry sulphate of magnesia, burnt alum, and other salts. But with the assistance of heat it was by degrees completely dissolved.

I ignited 10 grammes of this dry sulphate of alumina in a plaina crucible, as long as they lost any weight from the extrication of sulphurous acid; they left behind $2.9934 \mathrm{gr}$. of a loose white and light alumina. This sult, the dry sulphate of alumena, must therefore consist of

$$
\begin{array}{rrr}
\text { Sulphiric acir ... } & 70 \cdot 066 & 100 \cdot 000 \\
\text { Ainmina . . . . } & 29.934 & 42.722
\end{array}
$$

And if 42.722 parts of alumina contain $19 \cdot 96$ of oxygen, 100 parts must cortain $46 \cdot 726$.

In order to prepare the luydrate of alumina, I first attempted 
to separate the earth from alum by adding ammonia in excess. But in this I conld not succeed; for, when I burnt the alumina thus obtained, it always afforded first water, and then sulphurous acid and oxygen gas. Consequently ahrinina forms with the sulphuric acid an insoluble subsalt, which is but imperfectly decomposed by ammonia.

I therefore took the ahmina which had heen freed from sulphuric acid by complete ignition, dissolved it by long digestion in nitric acid, and precipitated it by adding to the solution caustic ammonia in excess. The gelatinous earta? was vell wasled on a filter, and slowly dried in the sun: when diry, it was rubbed to a fine powder, a arain digested with water, in order to separate the nitrate of ammonia, once more dried, and ignited in a small glass retort. At first pure water was evolved, but it was followed by a quantity of nitrous acid vapours, which culld only be completely expelled by a white heat. Consequently the nitric acid possesses the sane property as the sulphuric, of affording with alumina a subsalt, which is not completely decomposed by ammonia. The subnitrate of alumina has a considerable resemblance to the gelatinous silica, or to a stiff decoction of starch, and is easily obtained by rubling unburnt alumina with a little nitric acid : the mixture exhibits after a few moments an inflated starch-like mass.

I now dissolved alumina in muriatic acid, precipitated it with ammonia in great excess, and digested the precipitate for six hours with the solution, which remained strongly alkaline. The earth, when taken out of the filter, and well washed, was dried in the sum, finely powdered, and again exposed to the sun for a day. When ignited in a small retort, it afforded nothing but water, although a small portion of the earth itself was carried up with the water, and was collected like a fine dust in the receiver. The loss was somewhat increased by this circumstance.

This compound of waler and alumina left 64.932 per cent. of earth, which, being dissolved in nitric acid, showed no signs of sulphuric acid when examined by the test of a salt of baryta. Consequently 100 parts of dry alumina had been united with $\mathbf{5 4}$ of water: and this water contains 47.65 parts of oxygen : the alumina, on the other hand, as we have seen, contains only 46.726. I cannot insist on the perfect accuracy of either of these deterninations; but both of them are sufficiently near to the truth, to show that alumina, like the bases of salts already mentioned, is capable of combining with a quantity of wuter of which the oxygen is equal to that of the earth.

Alumina, after ignition, attracts moisture rery rapidly from the air, but retains it with a slight force; and the quantity defends on the hygrometrical state of the air. The wamth of 
the sun is sufficient to expel the greatest part of this water; and if we heat the alumina on a sand-bath, the whole of it is driven off; while the water in the true hydrate requires a red heat in order to be expelled. After some days, 100 parts of burnt alumina had absorbed 34.5 of water in an atmosphere saturated with moisture, hygr. $100^{\circ}$. Of this water it lost in a few days 18.5 parts, when the hygrometer stood at $7^{\circ}$, and the thermometer from $22^{\circ}$ to $25^{\circ}\left[72^{\circ}\right.$ to $\left.77^{\prime}\right]$; and its weight then remained stationary. It may be questioned in what state of combination this water was retained: certainly not in the same as in the hydrate.

\section{Silica.}

The silica, which is separated by acids from the liquor silicum, contains, after being dried, as is well known, a considerable quantity of water. I found tlat it made no difference whether I emplcyed silica that was precipitated at onee, or that was first separated in a gelatinous form.

Three portions of silica, which I had obtained by different analytical operations, were dried in the same saucer on a sandbath. When I ignited them after some hours' exposure to this heat, they all lost a quantity of water, which varied from 11.2 to $11 \cdot 3$ per cent.

The experiments upon the ignited alumina, and others upon the oxide of tin, which I shall hereafter relate, determined me to repeat these experiments at a subsequent time. I found that the oxide of tin, when dried in different temperatures, retained different proportions of water. I therefore weighed a portion of silica dried in the open air, and dried it again in a sand heat: the loss amounted to 26.8 per cent. Being left in the scale, its weight increased by degrees. I then dried it again very thoroughly, and ignited it; and I found the loss $14 \cdot 2$ per cent. It formed little transparent grains, which lost nothing of their transparency nor of their form by ignition. It seems, therefore, as if the water retained by the silica were precisely in the same state as that which ignited alumina absorbs from the air.

I had entertained hopes of being able to calculate the quantity of oxygen in silica, from that of the water retained in combination with it in a dry form; and the agreement of the three first experiments with each other made me suppose, that silica probably contains four times as much oxygen as the water combined with it ; and in this case the quantity would be 45 per cent. But $I$ no longer place any dependence on this mode of determination. It may perhaps be possible, at a future time, to ascertain the composition of silica from its combinations with the fluoric acid, or with the alkalis and the earths.

4. Oxide 


\section{Oxide of Iron.}

The experiments of $\mathrm{Mr}$. Lienbeck have for some time made it known in Sweden, that the yellow or brownish ore of iron called Meadow ore, "Rasenerz," contains the oxide in the form of a hydrate. My friend Mr. Hausmann of Cassel [now Professor of Technology at Gottingen, G.] wrote to me some months since that he had made the same remark, and had found from 19 to 21 per cent. of water in this hydrate, but considered the former number as the more correct. In this case the water would contrin a quantity of oxygen amounting to two-thirds of that of the oxide of iron, or the water would contain as much oxygen as had been required for converting the given quantity of iron into a protoxide. Although this does not agree with the laws which have been laid down, it is evident that this latter view of the subject may lead to very instructive consequences; and I was induced by it to add to these investigations the examination of the hydrate of the oxide of iron.

Mr. Liedbeck had found, in the ores which he examined, $2 ! \cdot 8,21 \cdot 1$, or 25 per cent. of volatile substances, of which water constituted about 20 . Together with the oxide of iron, he found mechanical mixtures of sand, clay, silica, and so forth, which being deducted from the oxide, left from 60 to 62 per cent. only: and this portion of pure oxide contains as much oxygen as the water combined with it.

I now examined some foreign specimens of this ore, and found in it $14 \cdot 4,13 \cdot 1,11 \cdot 6, \ldots$ per cent. of water, accordingly as the ore was dried in the sun, or in a sand heat. The ore was not magnetic before ignition, but became more or less so after ignition. Hence it must have contained a little combustible matter, which must have increased the loss by ignition. When the oxide was dissolved, after ignition, in muriatic acid, it left behind a little silica, swollen up into a semi-gelatinous form, which consequently appeared to have been chemically united with the oxide. But the admixture of forign substances was such as to render it impossible to determine the composition of this triple combination of water, silica, and oxide of iron, with so much precision, that the result might be of the least utility as a basis for calculation.

I now examined the yellow mass which is formed on weathering pyrites, and which I had often found to be free from sulphuric acid. The specimen taken from one piece lost during ignition 17.5 per cent.; from another 12 only. Both contained silica, and the first I afterwards found to exhibit traces of copper.

I then prepared some hydrates of iron, by decomposing the sulphate, the nitrate, and the muriate of the oxide, with caustic ammonia. 
ammonia. All these solutions afforded however a mixture of hydrate and subsalt, from which heat expelled first some water, and then some of the acid. The ignited hydrate lost in these experiments from 27 to 18.5 per cent.

I next digested the precipitate obtained from the nitrate with a great excess of caustic anmonia. The hydrate, when washed, and dried in the sunshine, now lost $22 \cdot 15$ per cent. : the fluid which escaped, was not pure water, but a strongly anmoniacal fluid. I had not therefore yct obtained a pure hydrate.

Two years and a half before, when I was examining the iron which contained silicium, I had left about 20 grammes of this iron, moistened with water, to oxidate spontancously. But the mass assumed by degrees a solid consistency, and even after the expiration of this time, was not completely oxidated throughout its substance. Not being able therefore to employ it for the analysis of silica, as I originally intended, I collected and dried a cuantity of the yellow ochre that was formed on it : but accidentally this substance was placed, with others that were to be dried, in a sand heat, and here in all probability lost a part of the water that was chemically combined with it ; for the hydrates of iron support but little heat, without assuming a darker colour, and losing part of their water. By ignition, its weight was further diminished 10 per cent. The red oxide that was left contained 8.2 per cent. of silica. I was therefore working again upon a triple combination of silica, oxide of iron, and water. The quantity, which I had to employ for this experiment, was too small; and was already consumed, so that I could not examine this preparation of iron with greater accuracy: but it was evidently an artificial combination resembling the foreign ore which I have already mentioned. This ore will undoubtedly become the subject of further investigation, and the comparative analysis of the artificial triple combination, obtained by the oxidation of iron containing silicium, will perhaps be indispensable ; for the ore is mixed in various and inconstant proportions with dust, and with different earthy substances, so that it can afford no certain results.

It is also obvious from what has been related, that it it diffcult to obtain a perfectly pure hydrate of iron, since the oxide combines, at the moment of precipitation, as well with acids as with ammonia, according to the degree of excess in which this alkali is present. I therefore allowed some iron filings to be uxidated in pure water, which I changed daily, and collected the hydrate. After some weeks I had obtained enough for an experiment on a small scale. I dried it in the sunshine for several days, and then ignited it in a platima crucible. It left 85.2 per cent. of red oxide, which was partially magnetic; a circumstance 
which I nttribute to some carion contained in the iron, wirch was mixed with the hydrate. This quantity of nxile contains 20.12 parts of oxygen, and the water combined with it 13 parts. Consequently in this experiment the oxide containcd twice as nuch oxygen as the water.

But in order that this proportion might have more than a single experiment for its support, I took some iron which contained less carbon, choosing for this purpose some harpsichord wire, n. 10 ; I suffered it to be oxidated in pure water, which was daily changed, in contact with a plate of platina, which accelerated the oxidation. After some weeks, I had again collected enough for examination. This hydrate, dried for several days in the sunshine, had a very light orange ycilow colour, and left after ignition a fine red oxide, not at all magnetic, which amounted to 85.5 per cent. Consequently in this experiment the hydrate had contained 14.5 per cent. of water, which confirms the preceding experiment; and we see that the hydrate of iron, which forms on iron in water, contains a quantity of water of which the oxygen is equal to half that of the oxide. It is however probable, as well from Mr. Liedbeck's experiments, as from others which will hereafter be mentioned, that the oxide of iron, when in comlination with other substances, is capable of taking up a quantity of water, of which the oxygen is equal to that of the oxide.

\section{Oxide of Tin.}

Ten grammes of pure tinfoil were oxidated in a glass flask by means of pure nitric acid; the fluid was evaporated, and the oxide ignited in the lask. It was of a light straw colour, and weighed $12 \cdot 72 \mathrm{gr}$. In another experiment I obtained only $12 \cdot 7 \mathrm{lgr}$. According to the former experiment, the oxide of tin consists of
Tin......... $[78 \cdot 62] \quad 100.0$
Oxygen...... $[21.38] \quad 27 \cdot 2$

It is a known fact tha oxide of tin, prepared with nitric acid, reddens litmus paper, but not after ignition. I thought at first that this might depend on some nitric acid adhering to it; but when the water, with which it was washed, no longer reddened the paper, the oxide still possessed the property. It was only deprived of it by pouring on it a little ammonia ; but the oxide now afforded, when ignited, water strongly impregnated with ammonia. The oxide of tin therefore has as much right to the denomination of an acid as the tungstic acid, and the columbic acid, or rather the " tantalic" oxide.

l dried some oxide of tin, which had been well washed, hut not treated with ammonia, in a sand heat. It lost by ignition 6.6 per cent. After some hours, when the sand-bath was considerably 
siderably colder, I repeated the experiment with a part of the sane oxide, which had remained on the sand. It now lost $9 \cdot 66$ per cent.: another portion, left for a longer time, lost 10.8 per cent. by ignition, and the next morning, when every thing had been completely cold for some hours, the loss amounted to 12.5 per cent.; the weather being in the mean time very damp and rainy. It is impossible to decermine which of these experiments ought to be preferred: and although this oxide, which approaches so nearly to the acids in its wature; when it retains the greatest portion of water, contains itself nearly twice as much oxygen as this water, still we can form no very decided conclusion from this circumstance.

It may be hoped that similar experiments on the water contained in the oxides of titanium and tantalium, on the tungstic acid, and other similar substances, will lead us to a more general and decided knowledge of the relation of water to these bodies, which occupy a middle rank between acids and bases.

But what are we to think of the attraction of a body for water, which retains this fluidoo slightly as to be overpowered by its expansive force at a moderate temperature? It must manifestly be the same power that causes filtering paper to attract moisture from the atmosphere, and sometimes to become heavier even during the operation of weighing it, and that exhibits the well known effects of hygroscopical substanees. Whether this force differs only in degree from that which is characterized by regularly defined relations between the bodies that are united, or whether it merely consists in a modification of superficial attraction, I do not venture to decide. With respect to the modifications of the force of elective attractions, there still remains much for us to investigate : for example, in what the force which causes a salt to be dissolved in water, in quantities dependent on the temperatures, differs from the force by which the same salt is capable of rendering solid a greater or less quantity of water of crystallization. Between these quantities there is no determinate and unalterable relation; for salts, which contain no water of crystallization at all, may be very soluble in water, for example, nitre, and muriate of potass; while others, which contain it very abundantly, are completely insoluble, as, for example, subsalts of iron and copper, carbonate of magnesia, and some others.

\section{Comlinations of Water with Salts. Water of Crystallization.}

Salts of potass. In no salt of potass that I have examined, the sulphate, nitrate, muriate, nor tartrate, have I found a trace of water of crystallization. If these salts are finely powdered, and dried in the sunshine, or in any other moderate warmth, 
they lose no more water during ignition. The nitrate of potass gives off in the operation oxygen gas, nitrous acid, and lastly nitrous gas, but does not afford a drop of liquid acid. The tartrate of potass, precipitated with nitrate of the protoxide of lead, afferded, for 100 parts of the well dried salt, 155.7 of tartrate of the protoxide of lead. Consequently, according to the analysis of this salt lately related, the tartrate of potuss consists of

$$
\begin{aligned}
& \begin{array}{lll}
\text { Tartaric acid.. } & 58.69 & 100 \cdot 0
\end{array} \\
& \text { Potass...... } 41 \cdot 31 \quad 70 \cdot 4
\end{aligned}
$$

Now 70.4 parts of potass contain 11.93 of oxygen, that is, with a very slight difference, the same quantity as the protoxide of lead that saturates 100 parts of the acid. The slight difference may depend on the unavoidable loss of a small quantity of tartrate of le $e_{i}$ in the experiment. Hence it is evident, that the tartrate of potass can contain no water of crystallization.

'The supertartrate of potass, on the contrary, or the crystals of tartar, contains water of crystallization, which cannot be expelled by heat. The salt employed for the preceding experiment had been made of pure tartaric acid with pure carbonate of potass, and was therefore perfectly free from lime. I precipitated the remaining portion of it with tartaric acid, I dried very carefully the powdered precipitate, and burnt 10 grammes of it in a platina crucible. The coaly alkaline mass was carefully washed with muriatic acid, the muriatic solution dried, and the salt ignited. $I$ obtained in one experiment 3.91 , and in another $3.915 \mathrm{gr}$. of muriate of potass. I found by another experiment, as Wollaston had already observed with respect to the oxalic acid, that the residuum of $10 \mathrm{gr}$. of supertarcrate of potass, after ignition, was sufficient to saturate $10 \mathrm{gr}$. of the supersalt: so that the potass must be combined with twice as much acid in the supersalt as in the neutral salt. But the muriate, which was obtained, answers precisely to $24 \cdot 8$ per cent. of pure potass, which must consequently form the superacetate with $70 \cdot 45$ of tartaric acid, and the remaining $4 \cdot 75$ parts must be water. Hence the superacetate of potass consists of

$$
\begin{array}{lr}
\text { Tartaric acid .. } & 70.45 \\
\text { Potass . . . . . } & 24.80 \\
\text { Water ...... } & 4.75
\end{array}
$$

This quantity of potass contains $4 \cdot 206$, and the water $4 \cdot 1,92$ parts of oxygen; consequently the water of crystallization in this salt contains exactly as much oxygen as the base. But since this water can only be expelled by the addition of a second base, and is exactly the same quantity as would have been combined with the excess of acid in a separate form of crystallization, this salt may be considered as a double salt, of which water is the second base. 
Salts of soda. While, according to the experiments whieh are here related, the salts of potass scem in reneral to be withont water of crystallization, those of soda on the cther hand contain it in alskidlance, but retain it with a very sight attraction, so that the greater number of them fail to powrler in a dry atmosphere. Hence it is very diffucult to obtain accurcte resulis with respect to them, since it may easily happen, that such a salt may begin to crumble away at the surface, before it is dry in the midills.

Sulphate of soda, in pure crystals, was washed with water, pulverised, and in grcat measure separated again from the water on hlotting paper, then dried in a press for twet.ty-four hours, between several folds of fresh blotting paper, and lastly dried again by slow degrees, and then ignited, in a platina crucible. In this process 30 grammes lost 16.8 in weight; consequently the salt contains 56 per cent. of water of crystallization, and must consist of

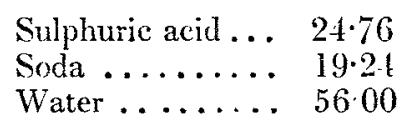

Now $19 \cdot 24$ parts of soda contain 4.953 of oxygen, and 56 of water $49 \cdot 42$; so that in this salt the water of crystallization contains exactly ten times as much oxygen as the base.

Acelate of sida. T'en grammes of acctate of soda, powdered, and dried in the open air, when exposed to the heat of a sand-bath, fell into dust, and lost $4.011 \mathrm{gr}$. of their weight. Five grammes of the acetate which had crumbled to dust, when muriatic acid was poured on it, and the salt was diried and ignited, afforcled 3.584 of muriate of soda. Consequently the acetate of soda must consist of

$$
\begin{aligned}
& \begin{array}{llll}
\text { Acetic acid } & 61.689 & 100 \cdot 0 & 36.95
\end{array} \\
& \begin{array}{llll}
\text { Soda..... } & 38 \cdot 311 & 62 \cdot 1 & 22 \cdot 94
\end{array}
\end{aligned}
$$

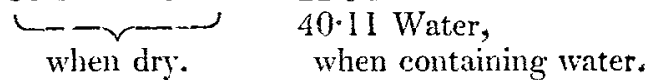

Now 22.94 parts of soda contain $5 . \$ 97$, and 40.11 of water 35.397 parts of oxygen ; and $5.897 \times 6=35.382$. Consequently in this salt the water of crystallization contains six times as much oxygen as the base.

Acetate of lime. In order in some measure to check this resulh, I converted $10 \mathrm{gr}$. of acetate of lime, which had been dried to a powder in a strong heat, into muriate of lime, and obtained from it $7.005 \mathrm{gr}$. which contained 3.5782 of pure lime. Consequently the acetate of lime consists of

$$
\begin{array}{llr}
\text { Acetic acid .. } & 64 \cdot 213 & 100 \cdot 00 \\
\text { Lime...... } & 35 \cdot 782 & 55 \cdot 74
\end{array}
$$

The quantity of soda, which decomposes 100 parts of acetate 
of lime, contains 15.89 parts of oxygen, and the quantity of the lime contained in 109 parts of this salt contains 15.71 of oxygen. Consequently this analysis appenrs to confirm the former, although they do not agree in the last figures; but they show at least that the quantity of oxygen required in a base, by 100 parts of acetic acid, camnot be materially different from these numbers.

Mwiate of ammonia. It appears from my analysis of this salt already related, that it consists of

$$
\begin{array}{ll}
\text { Muriatic acid....... } & 50.86 \\
\text { Ammonia........ } & 31 \cdot 95 \\
\text { Water .......... } & 17 \cdot 19
\end{array}
$$

[Since lime detaches 31.95 per cent. of ammoniacal gas from it, and nitrate of silver indicates 50.56 per cent. of muriatic acid; the rest being water. G.] But in 31.95 parts of ammoma there are 14.95 of oxygen, and in $17 \cdot 19$ of water there are $15 \cdot 17$ of oxygen. Consequently the water of crystallization of this salt must contain as mueh oxygen as the base. If the composition of water were ascertained with so much certainty, that we could depend on the last decimals of the determination, the result would indicate a small error in the analysis of the muriate of ammonia, and it would appear that I had found $\frac{199}{1090}$ too little ammonia in it. But it is scarcely worth while to attempt to make this corraction; and in other determinations, for instance, those of the muriatic acid, we cannot depend on the decimals. If however none of the analyses, which $I$ have published in this Essay, are perfectly correct, except by accident, still they appear to me to come near enough to the truth to allow us to employ them with safety in the investigation of the laws of the proportions of mixtures. It will only be possible to undertake the difficult task of discovering perfectly correct numerical expressions for these proportions, with better prospects of success, when these laws have been previously so well established, as to allow us to employ them with confidence in our analyses. [In this pursuit we may derive sufficient encouragement from the example of astronomers, who would never have been led by observation alone to the wonderful precision which the theory of the science has attained; and Mr. Berzelius, if I am not mistaken, will enjoy the lasting honour of having been the first [?] that has observed the possibility of following a similar path in chemical science, and not only of having pointed out this path, but of having already conducted us a considerable-way on in it, by the masterly analyses which he has performed in this investigation. G.]

Of the nitrate of anmonia I have spoien in the Second Continuation of this Fssay, which rclated to the capacity of saturation and the true composition of the nitric acid; and $I$ have there shown that, like the muriate, it contains a quantity of water Vol. 43. No. 190. Fet. 1814. 
of crystallization of which the oxygen is equal to that of the base.

Sulphate of ammonia. I had mixed 10 grammes of dry sulphate of ammonia with $30 \mathrm{gr}$. of caustic lime in a small glass retort, and then completely filled up the bulb and the neck of the retort with lime. I fitted to the mouth of the retort a small glass tube filled with caustic potass, and then leated the bulb slowly till it was completely ignited. When no more ammoniacal gas escaped through the opening of the tube, I withdrew the heat : the apparatus, when cold, had lost $2 \cdot 26 \mathrm{gr}$. of its weight. In another experiment it lost only $2 \cdot 25 \mathrm{gr}$. Now since the an!monia must saturate a quantity of sulphuric acid which contains three times as much oxygen as itself, this salt must consist of

$$
\begin{array}{lll}
\text { Sulphuric acid ...... } & 53 \cdot 1 \\
\text { Ammonia } \ldots \ldots \ldots \ldots & 22 \cdot 6 \\
\text { Water . . . . . . . . } & 24 \cdot 3
\end{array}
$$

This quantity of water contains 21.444 of oxygen, and the ammonia, according to my determination, 10.6 ; and $10.6 \times 2=$ $21 \cdot 2$.

In these experiments it is very difficult to drive out the ammonia completely, for a small portion of it almost always remains in the water which is condensed in the lime and the potass. But we sce from the experiment, that in this salt the water of crystallization contains twice as much oxygen as the base.

The oxalate of ammonia exhibits the singular spectacle of an ammoniacal salt falling to powder. According to some former experiments, the loss of weight during this efflorescence should amount to 16 per cent. But in several experiments I never obtained a greater diminution than 13.75 per cent. If now 100 parts of oxalic acid satmate a base which contains 21.2 parts of oxygen, the salt must be thus constituted:

$$
\begin{array}{cc}
\text { Oralic acid ..... } & 59 \cdot 37 \\
\text { Ammonia } \ldots \ldots . & 26.88 \\
\text { Water . . . . . . } & 13.75
\end{array}
$$

This quantity of ammonia contains $12 \cdot 586$ of oxygen, and the water $12 \cdot 134$. We may therefore assume it as demonstrated, that the base and the water of crystallization in this salt contain equal quantities of oxygen. The variation certainly depends only on some slight errors in the experiments.

Muriate of Zaryta. Seventeen grammes of finely powdered muriate of baryta, dried in the shate, lost $2 \cdot 505 \mathrm{gr}$. of their weight, when ignited in a platina crucible. Conseruently the crystallized salt consists of

$$
\begin{array}{ll}
\text { Muriacic acid .... } & 23.349 \\
\text { Baryta........ } & 61 \cdot 852 \\
\text { Water ........ } & 14.799
\end{array}
$$


This quantity of baryta contains $6 \cdot 495$, and the water $13 \cdot 05$ parts of oxygen. But $6.495 \times 2=12 \cdot 99$. The water of crystallization in this salt contains therefore twice as nuch oxygen as the base.

Sulphate of lime. From the analysis of ciystallized gypsum, described by Bucholz, we know that it is composed of the following parts :

$\begin{array}{ll}\text { Sulphuric acid.... } & 46 \\ \text { Lime } \ldots \ldots \ldots \ldots & 33 \\ \text { Water } \ldots \ldots \ldots \ldots & 21\end{array}$

This quantity of lime contains $9 \cdot 29$ of oxygen, and the water 18.53. Now $\dot{9} \cdot 29 \times 2=18 \cdot 58$. Consequently the water in this salt contains twice as much oxygen as the base.

Muriate of lime. I had collected and put by some years ago a quantity of fine crystals of muriate of lime. I pounded them quickly, and dried them between many folds of blotting paper, several times changed, in a press, until the sait communicated no more moisture to the paper. I weighed 10 grammes of the salt thus dried, in a well-stopped glass flask, then heated them in the same flask open, and lastly ignited them. The salt had lost $49 \cdot 603$ per cent. of its weight. The crystallized muriate of lime is therefore thus constituted:

$$
\begin{array}{lll}
\text { Muriatic acid ..... } & \mathbf{2 4} \cdot 686^{\circ} \\
\text { Lime .......... } & 25 \cdot 711 \\
\text { Water ......... } & 49.603
\end{array}
$$

Now 49.608 parts of water contain 43.774 of oxygen, and $25 \cdot 711$ of lime, $7 \cdot 24$; and $7 \cdot 24 \times 6=43 \cdot 44$. It is easy to see that a small excess of water could not here be avoided. Consequently the water of crystallization contains six times as much oxygen as the lime.

Sulphate of the protoxide of iron. Ten grammes of the sulphate of the protoxide of iron were very strongly heated in a glass retort, but not raised to a red heat: they lost $45.4 \mathrm{gr}$. of water. This salt consists therefore of

$$
\begin{array}{lll}
\text { Sulphuric acid ...... } & 28 \cdot 9 \\
\text { Protoxide of iron .... } & 25 \cdot 7 \\
\text { Water ......... } & 45 \cdot 4
\end{array}
$$

The oxygen of the water amounts to $40 \cdot 16$, and that of the protoxide to $5 \cdot 8$; and $5 \cdot 8 \times 7=40 \cdot 6$. Hence we see that the water of erystallization of this salt contains seven times as much oxygen as the base.

Sulphate of the protoxide of zinc. Ten grammes of this salt, being heated over a spirit lamp in a platina crucible, lost 36.15 per cent. But since the dry salt consists of 19.52 parts G 2 
of sulphuric acid and 50.48 of the base, it contains, when crystallized, Sulphuric acid .... $30 \cdot 965$

protoxide of zinc. . 32.585

Water ........ $36 \cdot 450$

The bace contains $6 \cdot 39$, and the water $32 \cdot 15$ parts of oxygen; but $6.39 \times 5=31.95$ : consequently the water contains five times as much oxygen as the base.

Sulphate of the oxide of copper. Ten grammes of this salt in crystals lost, when dried to a powder over a spirit lamp, $36 \cdot 3$ per cent. in weight. The crystallized sulphate of the oxide of copper consists therefore of

$$
\begin{array}{lll}
\text { Sulphuric acid .... } & 31 \cdot 57 \\
\text { Oxide of copper ... } & 32 \cdot 13 \\
\text { Water . . . . . . } & 36 \cdot 30
\end{array}
$$

since, according to the corrected analysis of the sulphate of baryta, 5 grammes of the sulphate of copper consist of $2 \cdot 477 \mathrm{gr}$. or $49 \cdot 55$ per cent. of sulphuric acid, and 50.45 per cent. of oxide of copper, or 101.82 parts of oxide of copper for 100 of sulphuric acid. The oxygen of the oxide of copper, being computed at 24.5 per cent. amounts to 6.32 , and that of the water to 32 : but $6.32 \times 5=31.6$; so that the water of crystallization contains five times as much oxygen as the base.

Nitrite of the protoxide of bismuth. Ten grammes of this salt, crystallized, and dried in the air after being powdered, were heated in a small retort to complete ignition. They afforded in one experiment $5 \cdot 13$, and in another $5 \cdot 12$ grammes of liquid nitric acid, not smoking. Consequently this salt must contain more water than is sufficient to exhibit the acid in its highest state of concentration. According to the very accurate experiments of $\mathrm{Mr}$. Lagerhjelm, the protoxide of bismuth contains 10.13 per cent. of oxygen ; 48.8 parts must therefore contain 4.9434, and inust consequently saturate 33.7 parts of nitric acid, [since 100 parts of nitric acid suppose $14 \frac{9}{3}$ of oxygen in the base which saturates them. G.] The remaining 17.5 parts, which make up the 100 , must have been water. But these contain 15.4 of oxygen; and $4.9434 \times 3=14.83$. We see therefore that, according to this experiment, which cannot be very accurate, from the readiness with which the atmospherical moisture decomposes the salt, the water of crystallization must contain three times as much oxygen as the base.

\section{Conclusions.}

I consider these examples, for which salts of so different natures have been selected, as sufficient to demonstrate the law, that " the oxygen of the water of crystallization is always an in- 
tegral multiple, or, as in the cases of the citric acid, and the subcarbonate of the oxide of copper, an integral submultiple of the oxygen of the base."

If we compare the oxygen of the water of erystallization with that of the acinl, we do not always find the same law observed: thus, in the sulphate of soda, for example, the oxygen of the water of crystallization is to that of the acid as $3 \frac{1}{3}$ to 1 , and in the sulphate of ammonia it is $\frac{2}{3}$ of that of the acid. Hence I have been led to the following rule: "In combinations of several oxygenized bodies, the oxygen of the component part, which contains the least of it, is an aliquot part of that of each of the other component parts."

But may not we discover, in combinations of this kind, a prevalent component part, of the oxygen of which, although its quantity may not be the smallest, that of the other parts must be multiples or submultiples? If, for example, in a subsalt, the acid contained one-third, and the water half as much oxygen as the base, the oxygen of the two former would stand in a regular relation to that of the latter, which might be regarded as the prevalent component part; but the oxygen of the water would not be a multiple of that of the acid, which in this case would be the least of the three. Among the few substances which I have had occasion to examine, I have met with no instance of this kind ; but it does not follow that the latter view mav not be a correct one. Since however every combination depends on the whole cum of the attractions of each of its component parts, the former mode of representation appears to me to be the more probable.

1 confess that we have at present too little experience to be able to set up such inferences as demonstrated laws. But we are obliged to adopt them at least as temporary suggestions, in order to our advancement towards a more certain theory: and I am convinced that all the opinions which I have here expressed will in general be confirmed as truths; although they may require numerous corrections, in proportion as more and more of the infinity of matter, which has hitherto eluded our researches, shall be made known by future investigations.

[To be continued.]

XXI. New Outlines of Chemical Philosophy. By Ez. WALKRR, Esq. of Lynn, Noifolk.

[Continued from p. 25]

\section{Comlustion.}

$\Gamma_{\text {here are very few bodies in nature, that do not contain either }}$ thermogen or photogen. All those bodies which are called comG 3 